\title{
Curbing Teen Dating Violence \\ Evidence from a School Prevention Program
}

V iolence between dating partners represents a significant public health problem. Approximately 20 percent of U.S. teens report dating someone who became violent with them. Victims face the threat of injury and also an elevated risk of substance abuse, poor health, sexually risky behavior, pregnancy, and suicide. Several school-based programs designed to prevent dating violence have been developed, but few have been assessed to determine what works. In particular, no study has examined the effectiveness of prevention programs for Latino teens, a large and growing group in public schools. Latinos may suffer disproportionate harms from dating violence because they may be less likely to report the problem or to seek help. A study led by RAND Corporation psychologist Lisa Jaycox assessed the effectiveness of a school-based program tailored to Latino students in inner-city public high schools. The study found that the intervention created a long-term improvement in students' knowledge of dating violence, reduced tolerance for aggressive or violent behavior, and improved teens' perceptions about getting help if they experienced dating violence. The study also found that Latino teens are most likely to turn to peers for help, and consequently, peer counselors are a promising source for assistance.

\section{"Ending Violence": A Law-Centered Intervention}

The study evaluated "Ending Violence," a three-class-session prevention program. Developed by a Los Angeles-based nonprofit group called Break the Cycle, the program focuses on the law, highlighting legal rights of victims of domestic violence and legal responsibilities of perpetrators. The teachers are bilingual, bicultural attorneys. This program has three distinctive features: it is brief (three class sessions), it is compatible with existing health curricula, and it focuses on the legal dimension of dating violence. This perspective is usually new to teens-especially Latino teens in families that have recently immigrated-who may be unfamiliar with their rights under U.S. law or how to exercise them. The program also informs students about its legal services program, in which attorneys are available to teens at no cost to help them with dating violence issues.

The evaluation was conducted in ninth-grade health classes in 11 Los Angeles Unified School District high schools. All of the school populations had more than 80 percent Latino students. Classes were assigned randomly to receive the "Ending Violence" curriculum or the standard health curriculum. A total of 2,540 students from ten schools and 110 classes participated. Researchers assessed the program's immediate impact and longer-term impact (six months later) on student knowledge and judgments about dating violence, student propensity to seek help, and the level of victimization and dating violence experienced by students after the intervention.

\section{The Intervention Improved Student Knowledge and Changed Views About Seeking Help}

The evaluation found that the intervention had modest but significant effects in three areas: student knowledge, attitudes about female-on-male violence, and attitudes about seeking help (see the table). Specifically,

- Teens who participated in the program had greater knowledge of laws related to dating violence and retained this knowledge six months later. 
Intervention Effects:

Increased Knowledge and Value of Getting Help from Attorneys Persisted Six Months After Intervention

\begin{tabular}{|l|c|c|}
\hline \multirow{2}{*}{} & \multicolumn{2}{|c|}{ Effects } \\
\cline { 2 - 3 } & $\begin{array}{c}\text { Was There } \\
\text { a Positive } \\
\text { Change } \\
\text { Immediately } \\
\text { After the } \\
\text { Program? }\end{array}$ & $\begin{array}{c}\text { Did the } \\
\text { Change } \\
\text { Persist } \\
\text { Six Months } \\
\text { After the } \\
\text { Program? }\end{array}$ \\
\hline $\begin{array}{l}\text { Knowledge about violence } \\
\text { and about dating violence }\end{array}$ & Yes & Yes \\
\hline $\begin{array}{l}\text { Acceptance of dating } \\
\text { violence }\end{array}$ & \multicolumn{2}{|c|}{} \\
\hline Female-on-male violence & Yes & No \\
\hline Male-on-female violence & No & No \\
\hline $\begin{array}{l}\text { Abusive or fearful dating } \\
\text { experiences }\end{array}$ & No & No \\
\hline $\begin{array}{l}\text { Usefulness of seeking } \\
\text { help from }\end{array}$ & \multicolumn{2}{|c|}{} \\
\hline Attorney & Yes & Yes \\
\hline Police & Yes & No \\
\hline Teacher & Yes & No \\
\hline School counselor & Yes & No \\
\hline School nurse & No & No \\
\hline Parents/family & \multicolumn{2}{|c|}{} \\
\hline Friends & \multicolumn{2}{|c|}{} \\
\hline Doctors & \multicolumn{2}{|c|}{} \\
\hline
\end{tabular}

- Participating teens were less accepting of female-onmale violence.

- The intervention did not change attitudes toward maleon-female violence, which were already strongly negative.

- The intervention also did not change the frequency of teens' violent or fearful dating experiences in the six months after the program.

- Students in the intervention group reported increased likelihood of seeking help from certain sources if they experienced dating violence.

\section{Getting and Giving Help}

A striking finding emerged from baseline surveys: Although students viewed various institutional sources of support as helpful, they would be far more likely to turn to informal sources, such as friends, parents, or family members, for help should they ever experience dating violence. Each student was asked to rate how helpful a particular source would be in addressing dating violence, and then was asked how likely he or she would be to talk to such a source for help. Students responded using a 5-point scale-rating a particular source's helpfulness from zero ("not at all help- ful") to four ("extremely helpful"), and rating the likelihood of talking to that source from "not at all likely" to talk to the source (zero) to "extremely likely" to talk to the source (four)-see the figure.

Notably, teens expressed positive views about the helpfulness of police, teachers, priests, and lawyers, but those views did not translate into a corresponding likelihood that they would turn to these sources for help if needed. The intervention improved teens' perceptions of police, lawyers, teachers, and school nurses as helpful, but the intervention improved their likelihood of seeking help only with respect to lawyers.

To explore student views of help-seeking behavior in greater depth, the research team conducted focus groups following the intervention. The sessions also explored attitudes about giving help to peers involved in dating violence. The focus groups underscored teens' propensity to turn to peers for help rather than to formal, institutional sources. Furthermore, most teens reported that they do not confide in or trust the adults in their social network. Teens also expressed reluctance to intervene in dating violence situations and did not perceive that their help would be effective.

\section{Implications for Strengthening Interventions}

Survey results also showed that teens who experience or witness aggression in their family life and among peers

\section{Surveys Showed Gaps Between the Perceived Helpfulness of Sources and Students' Likelihood of Turning to a Particular Source}

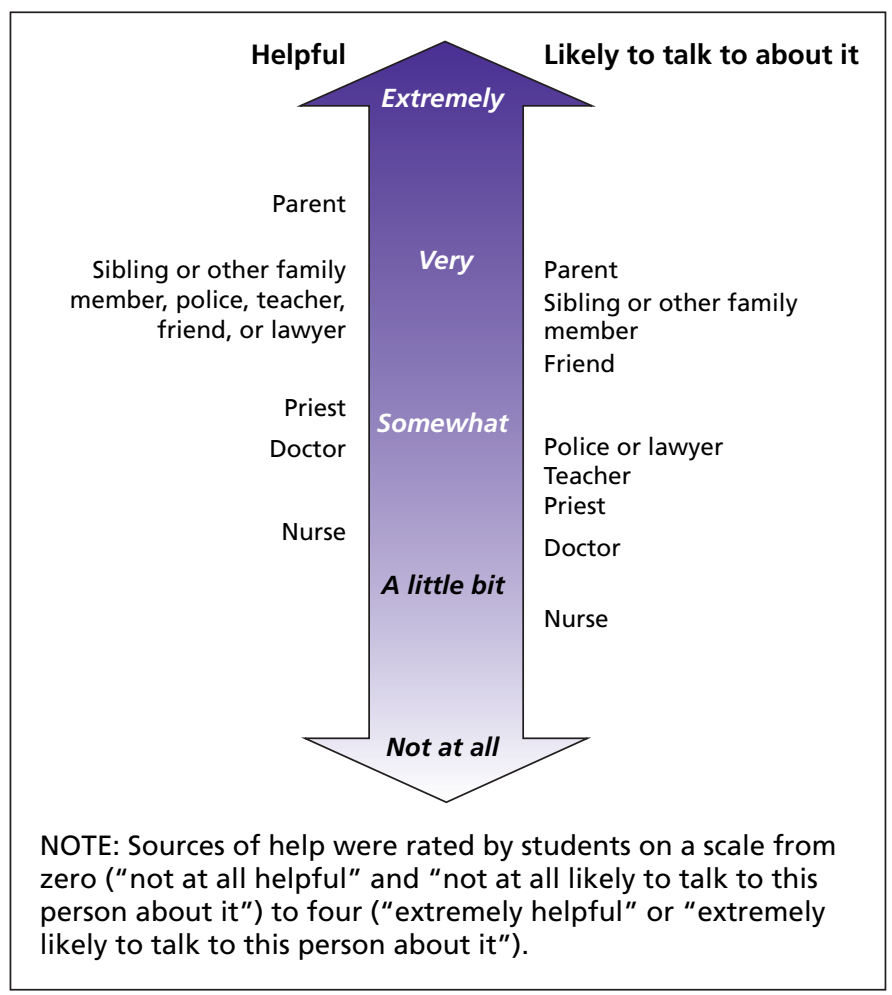


hold less negative attitudes about dating violence, so finding opportunities for reducing aggression in teens' daily lives may be helpful. In schools, a focus on reducing school and peer aggression and violence might bolster prevention efforts aimed at dating violence. Improving legal knowledge about dating violence may be a promising prevention element and could encourage victims of dating violence to seek help.

The results also suggest that another way to strengthen interventions is to target teen attitudes about seeking and giving help. Given Latino teens' inclination to seek help from peers, a promising avenue for intervention is the use of teens as peer educators to teach other teens about identifying and preventing dating violence. In addition, these teens can act as counselors who can link students with more formal sources of support, such as attorneys, police, and school personnel.

When giving help, teens would also benefit from a better understanding of how to aid others in an abusive relationship. The surveys and focus groups showed that teens are less likely to intervene in dating violence situations if they know the perpetrator. Intervention programs can educate teens about the importance of intervening when they witness an incident of violence or abuse among their friends and the best methods of doing so. Break the Cycle is already working with teens to develop such programs.
This Highlight summarizes RAND Health research reported in the following publications:

Jaycox LH, McCaffrey D, Eiseman E, Aronoff J, Shelley GA, Collins RL, and Marshall GN, "Impact of a School-Based Dating Violence Prevention Program Among Latino Teens: A Randomized Controlled Effectiveness Trial," Journal of Adolescent Health, Vol. 39, No. 1, in press. In-press corrected proof online at http://www.jahonline.org/inpress (as of June 30, 2006).

Ocampo BW, Shelley G, and Jaycox LH, "Latino Teens Talk About Help-Seeking and Help-Giving in Relation to Dating Violence," Violence Against Women, in press.

Quigley DD, Jaycox LH, McCaffrey DF, and Marshall GN, "Peer and Family Influences on Adolescent Anger Expression and the Acceptance of Cross Gender Aggression," Violence and Victims, Vol. 21, No. 5, 2006, in press, pp. 597-610.

\section{Related articles:}

Hickman LJ, Jaycox LH, and Aronoff J, "Dating Violence Among Adolescents: Prevalence, Gender Distribution, and Prevention Program Effectiveness," Trauma, Violence, and Abuse, Vol. 5, No. 2, 2004, pp. 123-142.

Jaycox LH, Aronoff J, and Shelley GA, “The Break the Cycle Evaluation Project," in Whitaker DJ, and Reese LE, eds., Preventing Intimate Partner and Sexual Violence in Racial and Ethnic Minority Communities: CDC's Demonstration Projects, Atlanta, Ga.: Centers for Disease Control and Prevention, National Center for Injury Prevention and Control, in press.

Jaycox LH, McCaffrey DF, Ocampo BW, Shelley GA, Blake SM, Peterson DJ, Richmond LS, and Kub JE, "Challenges in the Evaluation and Implementation of School-Based Prevention and Intervention Programs on Sensitive Topics," American Journal of Evaluation, Vol. 27, No. 3, 2006, pp. 320-336.

Ulloa EC, Jaycox LH, Marshall GN, and Collins RL, “Acculturation, Gender Stereotypes, and Attitudes About Dating Violence Among Latino Youth," Violence and Victims, Vol. 19, No. 3, June 2004, pp. 273-287. 


\section{RAND Research Areas}

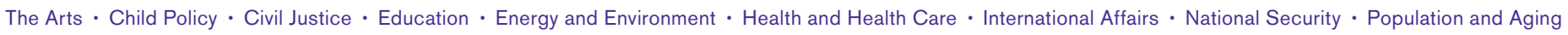
- Public Safety • Science and Technology • Substance Abuse • Terrorism and Homeland Security • Transportation and Infrastructure • Workforce and Workplace

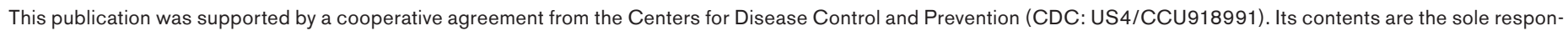
sibility of the authors and do not necessarily represent the official views of the CDC.

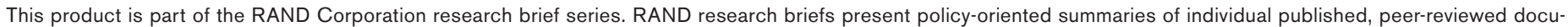

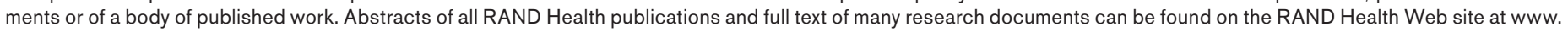

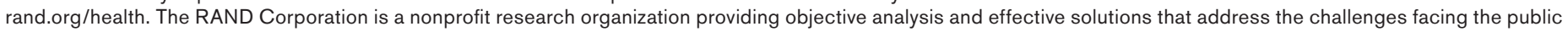

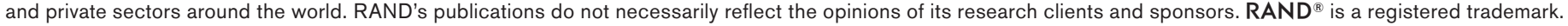

RAND Offices

Santa Monica, CA · Washington, DC · Pittsburgh, PA · Jackson, MS · Doha, QA · Cambridge, UK · Leiden, NL 
THE ARTS

CHILD POLICY

CIVIL JUSTICE

EDUCATION

ENERGY AND ENVIRONMENT

HEALTH AND HEALTH CARE

INTERNATIONAL AFFAIRS

NATIONAL SECURITY

POPULATION AND AGING

PUBLIC SAFETY

SCIENCE AND TECHNOLOGY

SUBSTANCE ABUSE

TERRORISM AND HOMELAND SECURITY

TRANSPORTATION AND INFRASTRUCTURE

WORKFORCE AND WORKPLACE
This PDF document was made available from www.rand.org as a public service of the RAND Corporation.

This product is part of the RAND Corporation research brief series. RAND research briefs present policy-oriented summaries of individual published, peerreviewed documents or of a body of published work.

The RAND Corporation is a nonprofit research organization providing objective analysis and effective solutions that address the challenges facing the public and private sectors around the world.

\section{Support RAND}

$\underline{\text { Browse Books \& Publications }}$

Make a charitable contribution

For More Information

Visit RAND at www.rand.org

Explore RAND Health

View document details

Limited Electronic Distribution Rights

This document and trademark $(s)$ contained herein are protected by law as indicated in a notice appearing later in this work. This electronic representation of RAND intellectual property is provided for noncommercial use only. Permission is required from RAND to reproduce, or reuse in another form, any of our research documents for commercial use. 